\title{
Hazard at Home: Dieffenbachia
}

\author{
Evdeki Tehlike: Difenbahya
}

\author{
Halise Akça' ', Emine Polat², Nilden Tuygun'1, Neslihan Gürcan Kaya², Can Demir Karacan \\ 'Department of Pediatric Emergency Medicine, Dr. Sami Ulus Maternity and Children Hospital, Ankara, Turkey \\ 2Department of Pediatrics, Dr. Sami Ulus Maternity and Children Hospital, Ankara, Turkey
}

\section{ABSTRACT}

Introduction: Childhood poisoning is commonly encountered in pediatric emergency medicine departments. As a result of a violation of the dieffenbachia plant body or parts of the leaves, effects can be seen in a spectrum from mild local irritation to death.

Case Report: Here, we report a 1-year, 11-month-old child patient, presenting with local irritation symptoms after violation of dieffenbachia plant leaves, who required supported treatment.

Conclusion: Ornamental plants in our homes should be considered a risk factor for toxicity.

Keywords: Dieffenbachia, poisoning, childhood

Received: 03.06.2013 Accepted: 01.08.2013

\section{ÖZET}

Giriş: Çocukluk çağında zehirlenmeler Çocuk Acil Servis başvuruları arasında sık görülmektedir. Difenbahya bitkisinin gövde ya da yaprak kısmının çiğnenmesi sonucunda hafif lokal irritasyondan ölüme kadar gidebilen etkiler görülebilmektedir.

Olgu Sunumu: Burada difenbahya bitkisinin yaprağını çiğnedikten sonra lokal irritasyon bulguları gelişen ve destek tedavisi ile düzelen bir yaş on bir aylık çocuk olgu sunulmuştur.

Sonuç: Bu olgu nedeniyle evlerimizde bulunan süs bitkilerinin zehirlenme açısından risk faktörü olabileceği akılda tutulmalıdır.

Anahtar Kelimeler: Difenbahya, zehirlenme, çocukluk çağı

Geliş Tarihi: 03.06.2013 Kabul Tarihi: 01.08.2013

\section{Giriş}

Çocukluk çağında zehirlenmeler Çocuk Acil Servis başvuruları arasında sık görülmektedir. Zehirlenmeler ilaç ya da ilaç dışı maddelere bağlı olarak meydana gelebilir. Halk arasında "ağlayan çiçek" olarak bilinen difenbahya kolay yetiştirilmesi ve çabuk büyümesi nedeniyle evlerde sıkça bulunan süs bitkilerindendir. Bitkinin gövde ya da yaprak kısmının çiğnenmesi sonucunda solunum yolunda tam tıkanıklığına kadar gidebilen orofaringeal ödem, oral mukoza ya da dilde ağrı, dilde hipertrofi, ağız mukozasında ülserasyon, sekresyonlarda artış ve konuşma zorluğu görülebilir. İnsan ya da hayvanlarda görülen difenbahya zehirlenmeleri ile ilgili İngilizce literatürde birçok olgu sunumu varken bu durum Türkçe literatürde oldukça nadir olarak bildirilmiştir. Burada difenbahya bitkisinin yaprağının çiğnemesi sonucunda dudaklarında şişlik ve kızarıklık yakınmaları ile başvuran bir çocuk olgu sunulmuştur.

\section{Olgu Sunumu}

Daha önce bilinen herhangi bir hastalığı olmayan bir yaş on bir aylık erkek hasta dudaklarında şişlik ve kızarıkık yakınmaları ile hastanemiz çocuk acil servisine getirildi. Hastanın öyküsünden yakınmaların hastaneye getirilmeden 2 saat önce başladığı öğrenildi. Hastanın gelişinde genel durumu iyi, bilinci açık, solunum sayısı 38/dk, kalp tepe atımı 123/dk ve kan basıncı 110/70 $\mathrm{mmHg}$ idi. Fizik muayenesinde dudaklarında şişlik ve dilinde hiperemi saptanan hastanın sistem muayeneleri normaldi. Laboratuvar incelemelerinde tam kan sayımı, kan biyokimyası normaldi. Nedeni saptamaya yönelik yapılan detaylı sorgulamada çocuğun bilinen hastalığının olmadığı, ilaç kullanmadığı, alerjen gıda ile temasının olmadığı öğrenildi. Ancak evde bulunan bir süs bitkisinin yaprağını ağzına aldığı, bir parçasını çiğnediği ve yakınmalarının bundan sonra başladığı anlaşıldı. Sorumlu bitki aileden temin edilerek incelendiğinde "Difenbahya" isimli bitki olduğu saptandı. Sıvı ve oksijen desteği verilen hastanın 24 saatlik takibinde vital bulguları stabil seyretti. Yakınma ve fizik muayene bulgularında tam düzelme olan hasta önerilerle taburcu edildi. 


\section{Tartışma}

Zehirlenmeler sık görülen ve hayatı tehdit eden bir sağlık problemidir (1). Ülkemizde Ulusal Zehirlenme Merkezinin verilerine göre tüm zehirlenmelerin \%56'sını, Amerika'da ise \%64,5'ini çocuklar oluşturmaktadır (2). Çocukluk çağındaki zehirlenmelerin $\% 67,4$ 'ü kaza sonucunda, \%25,9'u intihar amaçlı ve \%6,7'si tedavideki yanlışlıklar sonucu meydana gelmektedir. Genel olarak erkeklerde 1-5 yaş arasında, kızlarda ise 13-16 yaş arasında pik yapmakla beraber en sık okul öncesi dönemde görülmektedir. Zehirlenmelerin \%92'si ev ortamında, \%92,5'i ağızyoluyla ve \%81,3'ü tek bir madde alımına bağlı ortaya çıkar $(1,3)$. Olguların yaklaşık 2/3'lük kısmını ilaç alımları oluşturmaktadır. Illaca bağlı olanların başında analjezik ve antipiretikler gelirken ilaç dışı zehirlenmelerin ilk sırasında ise koroziv madde alımı gelir. Mortalitenin ilaç dışı zehirlenmelerde daha yüksek olduğunun bilinmesine rağmen Özdemir ve ark.'larının yaptığı çalışmada yoğun bakım ihtiyacı olan çocuk zehirlenme olgularının \%64,4'ünün ilaç kaynaklı olduğu gösterilmiştir (3).

Difenbahya, kolay bakımı nedeniyle evlerde süs bitkisi olarak sıklıkla yetiştirilen ve zehirli olduğu 17. yüzyıldan itibaren bilinen bir bitkidir. Ancak, difenbahya ile zehirlenme olgularının nadir olması nedeniyle genelde dikkatlerden kaçmaktadır.

Bitkinin yapısında sapanozitler, alkaloidler, siyanogenetik heterozitler, proteolitik enzimler, kalsiyum oksalat kristalleri ve okzalik asit bulunur. Bunların içerisinde kalsiyum oksalat kristalleri, okzalik asit ve proteazın zehirlenme ile ilgili tablodan sorumlu olduğu düşünülmektedir. Bitkinin genellikle ağız yoluyla alımı ya da göze teması ile toksik etkiler oluşmaktadır. Bu maddeler, inflamatuvar reaksiyon yaparak lokalize irritasyon bulgularına neden olur. Mikroskobik incelemelerde akut inflamasyona ait görünümler mevcuttur. Ancak bitkinin toksik etki oluşturma mekanizması net olarak bilinmemektedir. Hayvanlarda yapılan çalışmalarda inflamasyon yaratmak amacıyla difenbahya ekstreleri kullanılmıştır (4). Difenbahya, devetabanı ve ışkın gibi bitkiler içerdikleri kalsiyum oksalat tuzlarıyla sindirim kanalındaki irritasyonun yanı sıra akut hipokalsemi, böbreklerde akut tubuler nekroz ve çoklu organ yetmezliğine de yol açabilir (5).

Çocuklarda difenbahya alımının vücutta ortaya çıkardığı etkiler konusundaki veriler kısıtlıdır. Bir çalışmada difenbahya çiğneme sonrası özefajit ve sonrasında aortoözefageal fistül gelişen bir çocuk hasta bildirilmiştir (6). Literatürde ciddi hava yolu tıkanıklığı sonucunda trakeostomi gerektiren erişkin olgular belirtilmiştir (7). Hsueh ve ark'ları difenbahyanın göze teması sonrasında ağrı ve bulanık görmesi olan 3 olgu rapor etmişlerdir. Bu hastaların yakınmaları 5-18 saat içinde başlamış olup destekleyici tedavi ile bir haftada tam olarak düzelmiştir (8). Çeşitli hayvan çalışmalarında kedi ve köpeklerde bitkiye maruziyet sonrası gastrik ülserasyon ve solunum yolu tıkanıklığı gibi ciddi yan etkiler saptanmıştır (910). Bizim hastamızda sadece lokal irritasyon bulguları ortaya çıktı. Hastanın kliniğinin hafif seyretmesine rağmen ölümcül olabilecek komplikasyonlar açısından yakın klinik takip yapıldı. Takiplerde yakınmaların destek tedavisi ile gerilediği görüldü.

\section{Sonuç}

Çocukluk çağında zehirlenme olguları, acil servise başvuruların önemli bir kısmını oluşturmaktadır. Etkenin bilinmesi, doğru tanıya ulaşabilmek ve uygun tedaviyi düzenleyebilmek için hastanın ayrıntılı öyküsünün alınması gerekir. Evlerimizde bulunan süs bitkilerinin zehirlenme açısından risk faktörü olabileceği akılda tutulmalı ve ebeveynler çocukların korunması konusunda bilgilendirilmelidir.

Hasta Onamı: Yazılı hasta onamı bu olguya katılan hastanın ailesinden alınmıştır.

Hakem Değerlendirmesi: Dış bağımsız.

Yazar Katkıları: Fikir - H.A.; Tasarım - H.A.; Denetleme - N.T.; Malzemeler - N.G.K.; Veri toplanması ve/veya işlemesi - H.A.; Analiz ve/veya yorum - H.A, N.T.; Literatür taraması - H.A.; Yazıyı yazan - H.A.; Eleştirel İnceleme - E.P., C.D.K.

Çıkar Çatışması: Yazarlar çıkar çatışması bildirmemişlerdir.

Finansal Destek: Yazarlar bu çalışma için finansal destek almadıklarını beyan etmişlerdir.

Informed Consent: Written informed consent was obtained from the patient's parents.

Peer review: Externally peer-reviewed.

Author Contributions: Concept - H.A.; Design - H.A.; Supervision - N.T.; Materials - N.G.K.; Data Collection and/or Processing - H.A.; Analysis and/or Interpretation - H.A., N.T.; Literature Review - H.A.; Writer - H.A.; Critical Review - E.P., C.D.K.

Conflict of Interest: No conflict of interest was declared by the authors.

Financial Disclosure: The authors declared that this study has received no financial support.

\section{Kaynaklar}

1. Spiller HA, Beuhler MC, Ryan ML, Borys DJ, Aleguas A, Bosse GM Evaluation of Changes in Poisoning in Young Children 2000 to 2010 Pediatr Emer Care 2013; 29: 635-40. [CrossRef]

2. Oto Geçim N, İkincioğulları D, Harmancı N. Evaluation of childhood poisoning cases reported to national poison centre: five years of retrospective study. Turk Klin J Pediatr Sci 2006; 2: 1-4.

3. Özdemir R, Bayrakcı B, Tekşam Ö, Yalçın B, Kale G. Thirty-three-year experience on childhood poisoning. The Turkish Journal of Pediatrics 2012; 54: 251-9.

4. Gardner DG. Injury to the oral mucous membranes caused by the common houseplant, dieffenbachia: A review. Oral Surg Oral Med Oral Pathol 1994; 78: 631-3. [CrossRef]

5. T.C. Sağlık Bakanlığı, Refik saydam Hıfzıssıhha Merkezi Başkanlığı, Hıfzıssıhha Mektebi Müdürlüğü, Birinci Basamağa Yönelik Zehirlenmeler Tanı ve Tedavi Rehberleri, Bitkilerle Zehirlenmeler. 2007; 712: 171-3. 
6. Snajdauf J, Mixa V, Rygl M, Vyhnanek M, Moravek J, Kabelka Z. Aortoesophageal fistula-an unusual complication of esophagitis caused by Dieffenbachia ingestion. Journal of Pediatric Surgery 2005; 40: 29-31. [CrossRef]

7. Cumpston KL, Vogel SN, Leikin JB, Erickson TB. Acute airway compromise after brief exposure to a Dieffenbachia plant. J Emerg Med 2003; 25: 391-7. [CrossRef]

8. Hsueh KF, Lin PY, Lee SM, Hsieh CF. Ocular injuries from plant sap of genera Euphorbia and Dieffenbachia. J Chin Med Assoc 2004; 67: 93-8.
9. Müller N, Glaus T, Gardelle O. Extensive stomach ulcers due to Dieffenbachia intoxication in a cat. Tierarztl Prax ausg K Kleintiere heimtiere 1998; 26: 404-7.

10. Peterson K, Beymer J, Rudloff E, O'Brien M. Airway obstruction in a dog after Dieffenbachia ingetion. J Vet Emerg Crit care (San Antonio). 2009; 19: 635-9. [CrossRef] 